\title{
The Discussion on the Application of the Electrical Construction Technology of Prefabricated Buildings
}

\section{Guoxiu Cao}

Department of Building Equipment and Environmental Engineering, Guangxi Polytechnic of Construction, Nanning, Guangxi, China.

Postal code: 530007 , E-mail: 215961706@qq.com

Abstract: The acceleration of the development of economy and the construction of urbanization has promoted the development of the construction industry, and the construction technology of various construction projects has been continuously innovated. In the past, the building construction often suffered from disadvantages such as high energy consumption and generating large amounts of garbage. Modern construction techniques are actively improving these problems. Prefabricated construction techniques are widely used in the building construction, such as electrical pipeline construction, which makes electrical engineering construction more convenient and environmentally friendly. This paper mainly discusses the construction application of prefabricated electricity in the construction from the aspects of pipeline embedment, lightning protection grounding, the position of electric boxes and so on.

Keywords: Prefabricated; Building electrical engineering; Electrical construction technology

Under the current building background, the design concept and construction must meet the practical needs of energy conservation, environmental protection, and efficient operation. Guided by these advanced concepts, fabricated construction is a modern technology with rapid development and application, which has many advantages in construction and other aspects. Under active construction practices, prefabricated construction already has a complete technical system. Electrical design and construction are important parts of the building. Prefabricated construction is assembled by using prefabricated components which are prefabricated by the factory as required and assembled at the construction site. Generally, the construction site cannot be slotted and drilled to ensure the quality of prefabricated components. Prefabricated electrical construction can greatly improve the safety and reliability of construction and electrical systems, and make later maintenance management more convenient, can better meet today's energy saving and environmental protection requirements, and promote the construction industry to achieve better development. In the current situation of rising labor costs and stable economic development, the development of this technology is also a manifestation of concepts such as green and low-carbon, which is conducive to improving resource utilization and construction efficiency.

\section{The construction on the embedment of electrical pipelines}

\subsection{The construction in the wall}

When constructing electrical pipelines in structures such as walls, it is necessary to ensure that electrical pipelines can be embedded in the walls. During the construction, the outer diameter of the electrical pipeline is required to be less than or equal to $1 / 3$ of the thickness of the wallboard and other structures. Therefore, the design and construction personnel of electrical pipelines need to fully understand the size of the electrical pipeline and related building structures

Copyright (C) 2020 Guoxiu Cao

doi: $10.18282 /$ le.v9i5.1195

This is an open-access article distributed under the terms of the Creative Commons Attribution Non-Commercial License

(http://creativecommons.org/licenses/by-nc/4.0/), which permits unrestricted non-commercial use, distribution, and reproduction in any medium, provided the original work is properly cited. 
to effectively and accurately determine the precise relationship between the pipeline and building structures. In addition, the crossing of pipelines should follow the principle that no more than two electrical pipelines can be laid at the same location. In the actual construction, factors such as construction errors should also be considered.

\subsection{The relationship with buildings' steels and other structures}

In the building system, materials such as steels in load-bearing columns or wall reinforcement structures are very important. In electrical professional design and construction, it is necessary to be matched with these structures, but important structures such as steels cannot be required to change their design and construction requirements, let alone cutting off these important structures, otherwise it may increase the hidden danger of the building. Therefore, in the design and actual laying of pipelines, it is necessary to avoid the penetration of steels and other important structures to the greatest extent. At the same time, the distance of rebar in the prefabricated wall is based on the direction of the electrical pipeline, and the spacing is limited. Therefore, when laying the pipeline, it is necessary to follow the spacing standard, optimize the construction section that needs to penetrate as much as possible, and determine the feasibility of crossing the structure.

\subsection{The connection between electrical pipelines}

There are two types of pipeline connections: The pipeline connection of prefabricated wall and in-situ layer and the pipeline between prefabricated wall. When connecting the pipeline in the prefabricated wall and the cast-in-place layer, the position of the pipe in the cast-in-place layer can be adjusted according to the specific position of the pipeline. Firstly, it is necessary to accurately locate, and then adjust the specific pipe position to ensure that it corresponds to the embedded position of the prefabricated wall. When connecting electrical pipelines between prefabricated walls, first of all, it is necessary to accurately locate the placement position and size of prefabricated components, reduce errors, and consider factors such as laying errors, leaving appropriate adjustment space, which can be set in a unified location with pipeline connections. It is convenient to adjust the line pipe and connect pipelines by setting the wiring opening. After connection, it needs to pour concrete to seal the reserved opening. In addition, the laying and connection of electrical pipelines should meet the specific requirements of use, try to reducing imbedding pipelines in prefabricated walls and other components. In prefabricated houses, it is best to lay electrical pipelines in structures such as the empty space of floors, suspended ceilings, and cavity of walls, and do a good job of fireproof clogging.

\section{The design and construction of lightning protection grounding and distribution box}

\subsection{Lightning protection grounding}

Lightning protection grounding is a necessary project to ensure the normal use of electricity. It is necessary to select the main reinforcement in the cast-in-place column as the down lead line, preferably 2 pieces. If the structural column is also a prefabricated component, the hot galvanized flat steel should be exposed along the surface of the structural column as the down lead line, and the preferable size is $25 \mathrm{~mm} \times 4 \mathrm{~mm}$. The specific design should follow the actual structure of the building and lightning protection standards. The side lightning protection device can use the upper steel bar of the cast-in-place part of structures such as the laminated beam to set up the corresponding lightning protection device. If the building does not have a laminated beam, the hot galvanized flat steel is also used, which is connected to the steel bar on the upper layer of the laminated beam to form a closed loop to realize a complete lightning protection system.

\subsection{The position determination of weak electricity boxes and distribution boxes}

In a prefabricated building, each household is equipped with a strong electric box and a weak electric box to serve as a separate power source and signal source for each household, and there are a large number of concentrated electrical pipelines. Therefore, it should be avoided to install in prefabricated walls, so as to reduce the difficulty of cooperating with other constructions and the difficulty of retrofitting. If the distribution box and weak electricity box are arranged on both sides of the household wall, it is necessary to verify whether the building structure meets the requirements of sound insulation and fire protection. If the distribution box is arranged at other locations of the household, there are some 
situations, such as large incoming pipelines, concentrated circuits, and many cross-over pipelines. Especially when the outer diameter of the incoming pipe of the distribution box is up to the standard but the thickness of the cast-in-place layer is insufficient, it is necessary to try to divert the pipeline, or it can be solved by increasing the thickness of the castin-place layer, or adjusting the local construction plan to ensure that the floor and other structures still meet the seismic requirements after construction.

\section{The BIM technology for electrical construction}

With the development of the construction industry, the electrical systems of many large-scale prefabricated buildings are very complex, which brings great challenges to electrical construction. Therefore, BIM and other technologies begin to be used in electrical construction, which is strongly related to the electrical engineering. The three-dimensional model was used to connect various design information of the electrical system, comprehensively organize and process the relevant engineering information, and present it in an integrated manner. It collide and coordinate with other building constructions, thereby increasing the coordination between electrical design and related professions; The simulation and visibility of the BIM technology enable construction personnel to handle construction problems under special conditions or special construction requirements more transparently and comprehensively, improve the efficiency of information collection, pipeline design and other links, and provide comprehensive and systematic information references for later construction and transformation.

The BIM technology can be applied to complex pipe construction links such as cast-in-place parts and pipe connections. In some residential buildings, industrial plants and other projects, a combination of prefabricated method and cast-in-place method is used to increase the load capacity of the floor. The mixed floor is thick. For example, the common combination in residential buildings is $6 \mathrm{~cm}$ prefabricated board $+9 \mathrm{~cm}$ cast-in-place. In this case, in order to meet the construction requirements of electrical pipe superposition, the information in the structure can be summarized and optimized by the BIM technology, so as to avoid the problem of crossing of two or more pipes; The BIM technology is applied to the construction of pipe connection, which can improve the accuracy of the connection between prefabricated components or prefabricated and cast-in-place parts. 5. The application of the BIM to build a threedimensional model can accurately and reasonably determine the location of electrical pipelines. The information model and data are comprehensive, detailed, intuitive and easy to understand, which provides convenience for construction personnel.

\section{Conclusion}

In summary, the rapid development of prefabricated buildings has brought good development and application opportunities to related industries and technologies. Prefabricated buildings provide users with a variety of choice needs, but due to factors such as complex building structures and structural relationships, the design and construction of electrical projects are more difficult, and the inconsistent prefabricated construction quality and complex structure also increase the difficulty of the pipeline construction. While exploring the important aspects of pipeline laying and electrical box selection in electrical construction in prefabricated buildings, this paper briefly explores new technologies such as BIM in order to improve the quality and efficiency of electrical pipeline construction and make the electrical system more in line with the needs of prefabricated buildings and relevant construction standards.

\section{References}

1. Hu Guochen. The Analysis of Electrical Design and Supporting Technology in Prefabricated Buildings[J]. Shandong Industrial Technology, 2018 (15).

2. Wang Xiaoyi. Try to Explore the Modern Electrical Design of Prefabricated Buildings[J]. Science and Informatization, 2017 (27): 96-97.

3. Jing Xinhui. The Analysis of Electrical Design of Prefabricated Buildings[J]. Engineering Technology Research, 2018 (03): 213-214. 